Original Research Article

\title{
An experimental evaluation of anti-inflammatory activities of some combined NSAID preparations in albino rats
}

\author{
Rajashekar Y. R. ${ }^{1 *}$, Shobha S. N. ${ }^{2}$
}

${ }^{1}$ Department of Pharmacology,

${ }^{2}$ Department of Pathology, Adichunchanagiri Institute of Medical Sciences, BG Nagar, Mandya, Karnataka, India

Received: 23 February 2017

Revised: 24 February 2017

Accepted: 27 February 2017

\section{*Correspondence to:}

Dr. Rajashekar Y. R.,

Email:

rajashekar.yr@gmail.com

Copyright: (C) the author(s), publisher and licensee Medip Academy. This is an openaccess article distributed under the terms of the Creative Commons Attribution NonCommercial License, which permits unrestricted noncommercial use, distribution, and reproduction in any medium, provided the original work is properly cited.

\begin{abstract}
Background: Non-steroidal anti-inflammatory drugs are among the most commonly used drugs across the globe and they are also available over the counter for minor symptoms of pain and inflammation. Their toxicity profile limits their continued usage and search is continuing for the better effective and safer agent.

Methods: Interaction of paracetamol with diclofenac, ibuprofen and mefenamic acid were studied on carrageenan induced rat paw edema and cotton pellet induced granuloma models. Potentiation of these NSAIDs by paracetamol was also studied on same models.

Results: Addition of paracetamol did not increase anti-inflammatory activity of diclofenac, ibuprofen and mefenamic acid in both acute and subacute models of inflammation. Paracetamol found to potentiate the ibuprofen action in antiinflammatory model where as in subacute inflammatory model diclofenac action was potentited.

Conclusions: Our study does not support the rationality of various fixed dose combination of NSAIDs with paracetamol available in market. Either NSAIDs to be used individually or their dose need to be decreased in fixed dose combination.
\end{abstract}

Keywords: Anti-inflammatory action, Diclofenac, Fixed dose combinations, Ibuprofen, Mefenamic acid, Paracetamol

\section{INTRODUCTION}

Non steroidal anti-inflammatory drugs (NSAIDs) are among the most commonly prescribed drugs in clinical practice. More often they are taken without prescription for minor aches and pains. For more than 100 years, they have been used extensively for symptomatic relief, in patients of painful, inflammatory or arthritic conditions.

Following aspirin, ibuprofen is one of the most commonly used non-aspirin NSAIDs, though identified in early 1950 and it was introduced in clinical practice in the year 1969. Over the subsequent years, a new class of non-aspirin NSAIDs were identified and a series of novel agents was brought to the market. They are different in their chemical structure and they not only share anti- inflammatory, analgesic and anti-pyretic activities, but also several adverse effects. Toxicity profile involves mainly gastrointestinal system, though renal, cardiovascular, liver and skin associated problems are not infrequent. Some of the newly introduced drugs are found to have high efficacy and relatively less gastric toxicity, while none of them proved to be an ideal NSAID and thus search continues for it. Sir John Vane in the year 1971 first proposed that the beneficial and harmful effects of NSAIDs came from the blockade of cyclooxygenase enzymes in the body and thereby decreasing production of various prostaglandins. Numerous subsequent observations have reinforced this point of view. The combination of different NSAIDs with paracetamol appears to decrease their toxicity. Increased prostaglandin synthesis in the gastric mucosa by paracetamol could be 
responsible for its minimal gastric toxicity. ${ }^{1,2}$ Since the gastric damage depends upon the suppression of prostaglandin $\mathrm{E}_{2}$ biosynthesis which controls the mucosal blood flow and mucosal integrity.

Addition of paracetamol to NSAIDs, also thought to increase their efficacy by complementing analgesic and anti-pyretic actions. However this is not much backed by scientific studies.There are controversial reports regarding this. Co-administration of paracetamol with various NSAIDs has been shown to increase antiinflammatory and anti-arthritic efficacy of tolmetin in rats, to increase the anti-pyretic efficacy of aspirin in children and also to increase the analgesic efficacy of diclofenac with or without codeine in post surgical dental pain. $^{3-5}$

On the contrary, several reports indicate that ibuprofen alone is superior to combination with paracetamol in relieving pain due to surgery for impacted tooth, postepisiotomy pain, and osteoarthritis pain. ${ }^{6-8}$ There is paucity of information regarding the efficacy of diclofenac and mefenaemic acid, when co-administered with paracetamol. In view of these controversial reports and paucity of similar information about the NSAIDs, the present study was planned.

Aims and objectives of the study were to evaluate commonly used fixed dose combinations of NSAIDs viz paracetamol with ibuprofen, paracetamol with diclofenac \& paracetamol with mefenamic acid with regard to their anti- inflammatory activity and to study the interactions of paracetamol with commonly used NSAIDs viz ibuprofen, diclofenac and mefenamic acid in their sub anti-inflammatory doses on inflammation.

\section{METHODS}

Healthy adult albino rats weighing between 150-250gms were obtained from central animal house of the institution. They were randomly selected and divided into control and treatment groups. Each group had 6 animals and they were housed under standard laboratory conditions with free access to standard pellet diet and water ad libitum. They were acclimatized to the laboratory conditions for one week before starting the experiments.

\section{Drugs}

- Paracetamol 135mg/kg bw,

- Ibuprofen $108 \mathrm{mg} / \mathrm{kg}$ bw and $10 \mathrm{mg} / \mathrm{kg}$ bw

- Diclofenac $9 \mathrm{mg} / \mathrm{kg}$ bw and $1 \mathrm{mg} / \mathrm{kg}$ bw

- Mefenamic acid $135 \mathrm{mg} / \mathrm{kg}$ bw and $15 \mathrm{mg} / \mathrm{kg}$ bw

The drugs were obtained from laboratories in pure powder form of I.P grade. Rat equivalents of clinical doses of various drugs were calculated with the help of converting table as described by Paget \& Barnes and were used in present study. ${ }^{9}$

\section{Acute inflammation model}

Rats were kept starved overnight, but free access to water. On the day of experiment 30 minutes prior to carrageenan injection, the rats were administered per orally different drug preparations in $1 \%$ gum acacia using naso gastric tube. Acute inflammation was induced according to the technique of winter et al, by injecting $0.1 \mathrm{ml}$ of $1 \%$ carrageenan suspension in normal saline subcutaneously into the subplantar region of left paw. ${ }^{10}$ The paw edema volume was measured at zero hour and repeated at 30, 60, 180 and 300 minutes after carrageenan injection using mercury displaced manual plethysmograph. Average increase in paw edema volume at different time interval was calculated and the percentage inhibition of edema in various treatment group was calculated. Higher the percentage of inhibition, greater was the anti-inflammatory activity.

\section{Subacute inflammation model}

This method was according to Meier et al with some suitable modification. ${ }^{11}$ Overnight starved rats (with free access to water) were anaesthetized using Thiopentone sodium and they were fixed on operating table. After clipping the hairs in axillae, under aseptic condition two sterile cotton pellets (weighing $10 \mathrm{gms}$ ) were implanted subcutaneously through the small incisions made in axillae. After implantation, wounds were sutured and animals were allowed to recover from anaesthesia. Later the animals were administered different drug treatment daily for 10 days using nasogastric tube.

On $11^{\text {th }}$ day, the implanted cotton pellets were removed and dried overnight at $60^{\circ} \mathrm{C}$ to find their dry weights. The averaged granuloma dry weight of different treatment groups were compared with that of control for their sub acute anti-inflammatory activity.

\section{RESULTS}

All observations in the study were statistically analyzed by using ANOVA followed by Dunnet's test and student ' $\mathrm{T}$ ' test. The observed differences in treatment groups were considered to be significant at $\mathrm{P} \leq 0.05$.

The interaction of paracetamol with commonly used NSAIDs viz diclofenac, ibuprofen and mefenamic acid in their therapeutic as well as sub therapeutic equivalent doses was investigated, with respect to their acute and sub acute anti-inflammatory activities. The mean of the test result variables was calculated with standard deviation and tabulated as below.

\section{Carrageenan induced rat paw edema model}

In this model all the three NSAIDs namely diclofenac, ibuprofen and mefenamic acid in their therapeutic doses, individually and in combination with paracetamol showed to decrease paw edema volume significantly at 
60, 180 and 300 minutes (results at 30 and 300 minutes are shown in the Table). However higher \% inhibition was seen at 300 minutes, maximum of $32.73 \%$ with mefenamic acid and minimum of $25.56 \%$ with ibuprofen. Addition of paracetamol to them, did not affect their edema inhibiting property with values similar to that of their individual drugs. Paracetamol did not inhibit paw edema volume at any point of time interval and values were similar to that of control.

Table 1: Effect of various drug treatments on carrageenan induced rat paw edema model.

\begin{tabular}{|lllllll|}
\hline No. & Drug treatment dose (mg/kg) & $\mathbf{3 0} \mathbf{~ m i n}$ & $\mathbf{3 0 0} \mathbf{~ m i n}$ & $\mathbf{3 0} \mathbf{m i n}$ & $\mathbf{6 0} \mathbf{m i n}$ & $\mathbf{3 0 0} \mathbf{m i n}$ \\
\hline 1 & Control (1\% Gum acacia) & $0.41 \pm 0.07$ & $2.23 \pm 0.09$ & & & \\
\hline 2 & Diclofenac (9) & $0.40 \pm 0.02$ & $1.55 \pm 0.09^{* *}$ & 2.43 & 30.76 & 30.49 \\
\hline 3 & Ibuprofen (108) & $0.38 \pm 0.04$ & $1.66 \pm 0.09^{* *}$ & 7.31 & 25.27 & 25.56 \\
\hline 4 & Mefenamic acid (135) & $0.38 \pm 0.04$ & $1.50 \pm 0.03^{* *}$ & 7.31 & 30.76 & 32.73 \\
\hline 5 & Paracetamol (135) & $0.35 \pm 0.08$ & $2.00 \pm 0.08$ & 14.63 & 6.59 & 10.37 \\
\hline 6 & Paracetamol (135) +Diclofenac (9) & $0.33 \pm 0.02$ & $1.66 \pm 0.06^{* *}$ & 19.51 & 21.97 & 25.56 \\
\hline 7 & Paracetamol (135)+ Ibuprofen (108) & $0.36 \pm 0.04$ & $1.58 \pm 0.06^{* *}$ & 12.19 & 23.07 & 29.14 \\
\hline 8 & Paracetamol (135+ Mefenamic acid (135) & $0.38 \pm 0.02$ & $1.68 \pm 0.09^{* *}$ & 7.31 & 18.68 & 24.66 \\
\hline & ANOVA & 1.13 & 14.43 & & & \\
\hline
\end{tabular}

$\mathrm{n}=6$

Anova $\mathrm{F}_{7,40}$ at $\mathrm{p}=0.05-2.25$ Dunnet's Test $* \mathrm{p}<0.05 * * \mathrm{P}<0.01$

$\mathrm{P}=0.01-3.12$

Table 2: Effect of various drug treatments on carrageenan induced rat paw edema model (sub anti-inflammatory doses).

\begin{tabular}{|llllll|}
\hline No. & Drug treatment dose (mg/kg) & $\mathbf{3 0} \mathbf{m i n}$ & $\mathbf{6 0 0} \mathbf{m i n}$ & $\mathbf{3 0} \mathbf{m i n}$ & $\mathbf{6 0 0} \mathbf{m i n}$ \\
\hline 1 & Control (1\% Gum acacia) & $0.41 \pm 0.07$ & $2.23 \pm 0.09$ & & \\
\hline 2 & Paracetamol (135) +Diclofenac (9) & $0.38 \pm 0.03$ & $2.06 \pm 0.06$ & $7.31 \%$ & $7.62 \%$ \\
\hline 3 & Paracetamol (135)+ Ibuprofen (108) & $0.36 \pm 0.03$ & $1.91 \pm 0.08 *$ & $12.19 \%$ & $14.34 \%$ \\
\hline 4 & Paracetamol (135+ Mefenamic acid (135) & $0.36 \pm 0.03$ & $2.08 \pm 0.06$ & $12.19 \%$ & $6.72 \%$ \\
\hline & F-value & 0.37 & 1.57 & & \\
\hline
\end{tabular}

$\mathrm{n}=6$

Anova $\mathrm{F}_{3,20}$ at $\mathrm{p}=0.05-3.10$ Dunnet's Test $* \mathrm{p}<0.05$

In the same model when paracetamol was coadministered with sub-therapeutic doses of diclofenac, ibuprofen and mefenamic acid, only the antiinflammatory action of ibuprofen was enhanced significantly with the reduction of paw edema with \% inhibition of $17.58,17.48$ and 14.34 respectively at 60,180 and 300 minutes. The reduction of paw edema of diclofenac and mefenamic acid was not significantly altered by the addition of paracetamol.

\section{Cotton pellet induced granuloma model}

In this model, paracetamol alone did not decrease the granuloma dry weight significantly with the mean value of 13.63 and \% inhibition of 9.77 .

Diclofenac, ibuprofen and mefenamic acid individually decreased granuloma dry weight significantly with the mean values of $15.39,18.82$ and 19.32 and \% inhibition of 54.66, 44.56 and 43.09 respectively. Addition of paracetamol to these three NSAIDs showed very much similar mean values and \% inhibition as that of individual NSAIDs suggesting the facilitatory role of paracetamol in anti-inflammation.
Table 3: Effect of different drug treatment on cotton pellets granuloma dry weight.

\begin{tabular}{|c|c|c|}
\hline $\begin{array}{l}\text { Drug treatment } \\
\text { dose }(\mathrm{mg} / \mathrm{kg})\end{array}$ & $\begin{array}{l}\text { Granuloma dry } \\
\text { weight mg/100 gm } \\
\text { bw (Mean } \pm \text { S.E.M) }\end{array}$ & $\%$ inhibition \\
\hline $\begin{array}{l}\text { Control (1\% Gum } \\
\text { acacia) }\end{array}$ & $33.95 \pm 2.03$ & \\
\hline Diclofenac (9) & $15.39 \pm 1.21 * *$ & $54.66 \%$ \\
\hline Ibuprofen (108) & $18.82 \pm 0.98 * *$ & $44.56 \%$ \\
\hline $\begin{array}{l}\text { Mefenamic acid } \\
\text { (135) }\end{array}$ & $19.32 \pm 0.60 * *$ & $43.09 \%$ \\
\hline Paracetamol (135) & $13.63 \pm 1.54$ & $9.77 \%$ \\
\hline $\begin{array}{l}\text { Paracetamol } \\
(135)+\text { Diclofenac } \\
\text { (9) }\end{array}$ & $21.02 \pm 1.48^{* *}$ & $38.08 \%$ \\
\hline $\begin{array}{l}\text { Paracetamol } \\
(135)++ \text { Ibuprofen } \\
(108)\end{array}$ & $21.80 \pm 0.36^{* *}$ & $35.78 \%$ \\
\hline $\begin{array}{l}\text { Paracetamol } \\
(135)++ \text { Mefenami } \\
\text { c acid (135) }\end{array}$ & $22.56 \pm 1.73 * *$ & $33.54 \%$ \\
\hline F-value & 29.81 & \\
\hline
\end{tabular}


In the same model, the interaction of paracetamol with the sub-therapeutic doses of these three NSAIDs was also explored. The granuloma dry weight of diclofenac was reduced with the mean value of 26.26 and \% inhibition 17.79 and these values are of high statistical significance. Paracetamol addition did not benefit ibuprofen and mefenamic acid with mean values of 29.90 and 29.33 and $\%$ inhibition of 11.92 and 13.6 respectively.

\section{Table 4: Effect of different drug treatment on cotton pellets granuloma dry weight (sub anti-inflammatory doses).}

\begin{tabular}{|c|c|c|}
\hline $\begin{array}{l}\text { Drug treatment dose } \\
(\mathrm{mg} / \mathrm{kg})\end{array}$ & $\begin{array}{l}\text { Granuloma dry } \\
\text { weight mg/100 } \\
\text { gm bw } \\
(\text { Mean } \pm \text { S.E.M) }\end{array}$ & $\begin{array}{l}\% \\
\text { inhibition }\end{array}$ \\
\hline $\begin{array}{l}\text { Control (1\% Gum } \\
\text { acacia) }\end{array}$ & $33.95 \pm 2.03$ & \\
\hline $\begin{array}{l}\text { Paracetamol (135) } \\
+ \text { Diclofenac (9) }\end{array}$ & $26.26 \pm 1.35^{*}$ & $17.79 \%$ \\
\hline $\begin{array}{l}\text { Paracetamol (135)+ } \\
\text { Ibuprofen }(108)\end{array}$ & $29.90 \pm 0.96$ & $11.92 \%$ \\
\hline $\begin{array}{l}\text { Paracetamol (135)+ } \\
\text { Mefenamic acid (135) }\end{array}$ & $29.33 \pm 1.67$ & $13.60 \%$ \\
\hline F-value & 0.78 & \\
\hline
\end{tabular}

Anova $\mathrm{F}_{3,20}$ at $\mathrm{p}=0.05-3.10$ Dunnet's Test $* \mathrm{p}<0.05$

\section{DISCUSSION}

As already described, the main objective of the study was to evaluate the interaction of different NSAIDs like diclofenac, ibuprofen and mefenamic acid in their therapeutic and subtherapeutic equivalent doses with paracetamol in rats.

The anti-inflammatory activity of diclofenac, ibuprofen and mefenamic acid as observed in the present study both in acute and subacute inflammatory models are well established in their subtherapeutic equivalent doses. The combination of paracetamol with these agents (as equivalent to market preparations) has not affected the inflammatory activity of these NSAIDs. There is paucity of information in the literature regarding similar studies. However, ibuprofen alone was shown to be better than its combination with paracetamol in earlier studies. ${ }^{6,7}$ Which agrees with the ideas of the present study with ibuprofen. In acute and subacute models of inflammation diclofenac, ibuprofen and mefenamic acid in their subantiinflammatory dose, when co-administered along with paracetamol, it potentiated the anti-inflammatory activity of ibuprofen in acute model and that of diclofenac in subacute model. However, it failed to modify the anti inflammatory activity of mefenamic acid in both the models.

It is enigmatic why paracetamol did not influence anti inflammatory activity of mefenamic acid in both the models and variably modified anti -inflammatory activity of diclofenac and ibuprofen. The potentiation of antiinflammatory activity of diclofenac in sub-acute and that of ibuprofen in acute model by paracetamol could be attributed to differences in pharmacokinetic features such as plasma $1 / 2$ life and distribution of these two drugs.

These findings of present study agree with the earlier reports in which paracetamol has been shown to increase the anti-inflammatory activity of aspirin and tolmetin., ${ }^{3,12}$ Though there are no similar reports regarding the enhancement of anti -inflammatory activity, when paracetamol is combined with diclofenac, ibuprofen and mefenamic acid.

If these results could be extrapolated to clinical situation, this study clearly conclude that claimed advantages of FDC of such anti-inflammatory drugs with paracetamol and the study also supported the potentiation of antiinflammatory activity significantly, but in a variable way. Further clinical studies are required to confirm this.

\section{CONCLUSION}

Addition of paracetamol to therapeutic equivalent dose of diclofenac, ibuprofen and mefenamic acid did not significantly alter anti-inflammatory activity. But paracetamol with subanti-inflammatory doses with these NSAIDs showed variable effects, potentiated ibuprofen in acute model and diclofenac in subacute model, while not affecting the mefenamic acid and thus questions the rationality of available fixed dose combination of NSAIDs with paracetamol in market and demands either the decrease in the recommended dose or finding a newer safe alternative drug.

\section{Funding: No funding sources}

Conflict of interest: None declared

Ethical approval: The study was approved by the Institutional Ethics Committee

\section{REFERENCES}

1. Konturek SJ. Prevention of ethanol and aspirin and aspirin induced gastric mucosal leions by paracetamol and salicylates in rats: role of endogenous prostaglandins. Gut. 1972;23:536-40.

2. Von Kolfchoten AA. Protection by paracetamol against various gastric irritants in the rat. Toxicol. App Pharmacol. 1987;69:37-42.

3. Wong S, Gardocki JF. Anti-inflammatory and antiarthtritic evaluation of acetaminophen and its potentiation of tolmetin. J Pharmacol. Exp Ther. 1983;226:626-32.

4. Steel RW. Oral antipyretic therapy: Evaluation of aspirin-acetaminophen combination. Amer J Child. 1972;123:204-07.

5. Breivik EK. Combining diclofenac with acetaminophen or acetaminophen-codine after oral surgery. Pharmacol. Ther. 1999;66:625-35. 
6. Copper SA. The relative efficacy of ibuprofen in dental pain. Compend. Contin. Edu. Dent. 1988;7:578-88.

7. Hazra A. A comparative evaluation of ibuprofen and ibuprofen+paracetamol in post-episiotomy pain. Ind. J Clin. Practice. 1996;7:49-53.

8. Singh GP, Singla R. Comparative evaluation of ibuprofen and ibuprofen+paracetamol combination in osteoarthritis. In. Med. Gaz. 1997;131:236-42.

9. Ghosh MN. Fundamentals of experimental pharmacology, Calcutta: Scientific book agency. Calcutta. 1984;230:148-53.

10. Turner RA. Screening methods in pharmacology, New York and London, Academic Press Inc. 1965:322-23.
11. Vogel HG, Vogel WK. Drugs discovery and evaluation, Pharmaclogical Assays, Germany, Springer Publications. 1997:758-59.

12. Graham DY. Non steroidal anti-inflammatory effect of sulindac sulfoxide and sulfide on gastric mucosa. Clin Pharmacol. Ther. 1985;38:65-70.

Cite this article as: Rajashekar YR, Shobha SN. An experimental evaluation of anti-inflammatory activities of some combined NSAID preparations in albino rats. Int J Basic Clin Pharmacol 2017;6:83741. 